\title{
Responsible implementation of expanded carrier screening
}

\author{
Lidewij Henneman $^{1}$, Pascal Borry ${ }^{2}$, Davit Chokoshvili ${ }^{2,3}$, Martina C Cornel ${ }^{1}$, Carla G van $\mathrm{El}^{1}$, \\ Francesca Forzano ${ }^{4}$, Alison Hall ${ }^{5}$, Heidi C Howard ${ }^{6}$, Sandra Janssens ${ }^{3}$, Hülya Kayserili ${ }^{7}$, Phillis Lakeman ${ }^{8}$, \\ Anneke Lucassen ${ }^{9}$, Sylvia A Metcalfe ${ }^{10}$, Lovro Vidmar ${ }^{11}$, Guido de Wert ${ }^{12}$, Wybo J Dondorp ${ }^{12}$ and \\ Borut Peterlin ${ }^{\star} 11$ on behalf of the European Society of Human Genetics (ESHG)
}

\begin{abstract}
This document of the European Society of Human Genetics contains recommendations regarding responsible implementation of expanded carrier screening. Carrier screening is defined here as the detection of carrier status of recessive diseases in couples or persons who do not have an a priori increased risk of being a carrier based on their or their partners' personal or family history. Expanded carrier screening offers carrier screening for multiple autosomal and X-linked recessive disorders, facilitated by new genetic testing technologies, and allows testing of individuals regardless of ancestry or geographic origin. Carrier screening aims to identify couples who have an increased risk of having an affected child in order to facilitate informed reproductive decision making. In previous decades, carrier screening was typically performed for one or few relatively common recessive disorders associated with significant morbidity, reduced life-expectancy and often because of a considerable higher carrier frequency in a specific population for certain diseases. New genetic testing technologies enable the expansion of screening to multiple conditions, genes or sequence variants. Expanded carrier screening panels that have been introduced to date have been advertised and offered to health care professionals and the public on a commercial basis. This document discusses the challenges that expanded carrier screening might pose in the context of the lessons learnt from decades of population-based carrier screening and in the context of existing screening criteria. It aims to contribute to the public and professional discussion and to arrive at better clinical and laboratory practice guidelines.
\end{abstract}

European Journal of Human Genetics (2016) 24, e1-e12; doi:10.1038/ejhg.2015.271; published online 16 March 2016

It is estimated that there are more than 1300 recessively inherited disorders (autosomal and X-linked), whose symptoms range from the very mild to severe, cumulatively affecting at least 30 in every 10000 children. ${ }^{1,2}$ This means that approximately $1-2$ in 100 couples are couples who are at risk of having a child affected with a recessive genetic condition. ${ }^{3}$ Currently, the standard practice is to offer carrier testing to individuals at adult age who have a family history of a particular recessive disease; to the partners and relatives of identified carriers, or to the partners of people with the disease. However, in this way, only a minority of carrier couples will be identified, since the majority of affected children are born to couples with no previous known family history, and only a minority of relatives in high-risk families request carrier testing. ${ }^{4}$ The document was prepared by members of the Public and Professional Policy Committee (PPPC) of the European Society of Human Genetics (ESHG) and approved by the ESHG Board on 6 September 2015. This document is also endorsed by the British Society for Genetic Medicine (BSGM) Board. A summary of this document with the recommendations will be published in print in the European Journal of Human Genetics. ${ }^{5}$ The below full version with extensive references is published online only.
Basic concepts of carrier screening

Carrier screening is defined here as a type of medical investigation to detect whether or not carrier status for a recessive disorder is present in a couple or a person, who does not have an a priori increased risk of being a carrier based on their or their partners' personal or family disease history. Carrier screening offered before or during pregnancy determines a couple's risk of having a child with a recessive inherited disorder, thereby facilitating reproductive choices for those at a high risk of having a child with a serious genetic disorder. Identifying carriers of either autosomal recessive or X-linked disorders has the potential to benefit prospective parents. When both partners are identified carriers of the same autosomal recessive disease, they have a one in four risk in each pregnancy of having a child affected by this disease. For X-linked disorders, half of the male offspring of a carrier mother will typically be affected. In this document we define 'carrier couples' as couples at risk of having offspring with an autosomal recessive or X-linked disorder.

Carrier screening can be considered at different life stages, for example, by individuals or couples before pregnancy (preconception carrier screening) or even before relationships commence (premarital,

\footnotetext{
${ }^{1}$ Department of Clinical Genetics, Section Community Genetics and EMGO Institute for Health and Care Research, VU University Medical Center, Amsterdam, The Netherlands; ${ }^{2}$ Centre for Biomedical Ethics and Law, University of Leuven, Leuven, Belgium; ${ }^{3}$ Centre for Medical Genetics Ghent, University Hospital Ghent, Ghent, Belgium; ${ }^{4}$ Medical Genetics Unit, Ospedali Galliera, Genova, Italy; ${ }^{5} \mathrm{PHG}$ Foundation, Cambridge, UK; ${ }^{6}$ Centre for Research Ethics and Bioethics, Uppsala University, Uppsala, Sweden; ${ }^{7}$ Department of Medical Genetics, Koç University School of Medicine (KUSoM), Istanbul, Turkey; ${ }^{8}$ Department of Clinical Genetics, Academic Medical Center, Amsterdam, The Netherlands; ${ }^{9}$ Department of Clinical Ethics and Law (CELS), University of Southampton and Wessex Clinical Genetic Service, Southampton, UK; ${ }^{10}$ Murdoch Children's Research Institute and Department of Paediatrics, The University of Melbourne, Parkville, VIC, Australia; ${ }^{11}$ Clinical Institute of Medical Genetics, Ljubljana University Medical Centre, Ljubljana, Slovenia; ${ }^{12}$ Department of Health, Ethics \& Society, Research Schools CAPHRI and GROW, Maastricht University, Maastricht, The Netherlands

*Correspondence: Professor B Peterlin, Clinical Institute of Medical Genetics, Ljubljana University Medical Centre, 1000 Ljubljana, Slovenia. E-mail: borut.peterlin@guest.arnes.si Received 10 September 2015; revised 9 November 2015; accepted 18 November 2015; published online 16 March 2016
} 
or pre-relationship carrier screening, for example, high-school screening), and by women during pregnancy and their partners (prenatal carrier screening). There are advantages and disadvantages to screening at each particular stage. For example, although prenatal screening is considered the most practical since pregnant women generally come to medical attention, the preconception period might be considered better timing with regard to the primary aim of screening because it results in more reproductive options being available besides prenatal diagnosis - thus in maximizing meaningful choices- ${ }^{6}$ including preimplantation genetic diagnosis (embryo selection), use of non-carrier donor sperm and/or oocytes, refraining from pregnancy or adoption. Furthermore, in some cultures, where the focus of screening is on spouse/partner selection or carrier matching, changing the choice of partner to prevent disease is an option.

Carrier screening should be distinguished from newborn screening, which aims to detect newborns with serious treatable disorders for early treatment and prevention, and their roles are considered complementary. ${ }^{7}$ For some disorders, newborn screening automatically yields carrier status information as an unsolicited finding, because of the nature of the test being employed. Since carrier status has no immediate implications for the child, disclosure of this information to parents has raised much debate. ${ }^{8}$

Carrier screening can be offered on an occasional basis, organised as a population-based offer as part of a screening programme irrespective of risk status, or aimed at specific high-risk populations based on ancestral background. Carrier screening can be offered to individuals or couples. For couples, screening tests can be performed simultaneously or sequentially (after the first partner tests positive). Moreover, test-results can be communicated to partners individually (ie, disclosure of individual test-results) or couple-based (ie, positive results are communicated only to those couples in which both partners are found to be carriers).

Although in most Western countries there is consensus that the aim of reproductive screening, including carrier screening, should be to enhance reproductive autonomy and enable meaningful reproductive choices, from a global perspective there are different views. In some communities with a high burden of severe disease, population-level prevention is regarded as the appropriate aim of carrier screening, and in those cases reduced birth rates of affected children may be regarded as the measure of success. ${ }^{9}$ Furthermore, although not to date considered a primary aim, carrier screening might also contribute to early therapeutic procedures in the neonatal (and potentially also prenatal) period for certain conditions; closer monitoring and surveillance - and hence earlier diagnosis - of infants born to known carrier couples which consequently might reduce morbidity and mortality related to these disorders.

\section{From single diseases to expanded screening panels}

So far, carrier screening has been performed for relatively common, recessive disorders associated with significant morbidity and reduced life-expectancy. Examples are carrier screening for cystic fibrosis (CF) (offered in countries including the United States, Australia and Italy) and beta-thalassaemia (offered in, eg, Cyprus, Sardinia, Israel and Turkey). Other examples include panels of specific disorders targeted at specific communities, such as people with Ashkenazi Jewish (AJ) ancestry, which has resulted in a substantial lowering of the number of children born as affected with diseases such as Tay-Sachs disease. ${ }^{10}$ Disadvantages of ancestry-based screening are that diseases are not limited to specific groups and it is difficult to define who is at risk because of multi-ethnic backgrounds. ${ }^{11}$ In contrast to a diagnostic setting, where signs/symptoms lead to suspicion of a particular condition, carrier screening usually involves panels of sequence variants that are the most frequent and known to affect function.

With the introduction of new (faster and cheaper) genetic technologies, it is now possible to detect a much larger set of sequence variants, but also to simultaneously screen for many different diseases at a faster turnaround time without significantly increasing costs. Moreover, while some current screening programmes are ancestrybased, expanded carrier screening (sometimes referred to as 'panethnic' or 'universal') allows testing of all individuals regardless of ancestry, which in this respect increases equity and potentially reduces the risk of stigmatisation of ethnic groups. An increasing number of commercial laboratories, both in North America, Australia and in Europe, already offer panels for carrier screening for over 100 diseases. However, were these panels to be implemented in routine health care, this could pose major challenges for health care professionals. Responsible implementation of expanded genetic carrier screening raises many technical, ethical, legal and social questions, including among others: Which diseases and sequence variants should be included in the panels and on what basis will these decisions be made? What are public and professional attitudes and preferences towards expanded carrier screening panels? How can pre- and posttest education and counselling be optimised to facilitate informed decision making?

\section{Challenging the principles of carrier screening}

A distinguishing feature of screening compared with diagnostic testing is that a test is usually offered to people without any sign or symptoms of a specific health problem and without $a$ priori increased risk. To justify screening, a screening programme has to meet certain criteria, and in many countries the Wilson and Jungner criteria remain the used standard, albeit with some modification for developments in genetics. ${ }^{12}$ For reproductive screening - as stated above - the aim is generally not for early diagnosis/prevention and treatment, but to facilitate reproductive decision making. ${ }^{13,14}$ An important screening criterion is that the natural course of the disease screened for should be adequately understood, and that an acceptable and reliable test should be available with known sensitivity, specificity and predictive values. In reproductive screening where couples may be faced with the choice of avoiding or terminating a pregnancy, their autonomous decision making should be facilitated. In 2003, the ESHG issued a document on the principles, techniques, practices and policies that impact population genetic screening programmes in Europe. This opined that 'genetic screening goals and the target population must be well defined; laboratory quality control stringent, with limits of results clearly delineated; the confidentiality of the information protected by authorities; procedures to protect individual and family privacy established in advance; voluntary participation; genetic counselling offered and educational programmes in place; and long-term outcomes monitored and evaluated'. ${ }^{15}$ Expanded carrier screening panels pose a challenge to these criteria and principles, and any implementation will need a justification in terms of proportionality in which the advantages outweigh the disadvantages. However, when the topic was discussed by the UK's Human Genetics Commission, there was a definite view that, while such an extended range of carrier screening did present certain challenges to health services, there was no reason for such screening not to be pursued. ${ }^{16}$

In 2013, the American College of Medical Genetics (ACMG) published a position statement outlining the important issues related 
to prenatal/preconception expanded carrier screening. ${ }^{17}$ The more extensive joint statement of the ACMG, American College of Obstetrics and Gynecologists (ACOG), National Society of Genetic Counselors, Perinatal Quality Foundation, and Society for Maternal-Fetal Medicine in $2015^{11}$ suggests, among others, the components of consent for expanded carrier screening, information related to post-counselling, criteria for conditions to be included on expanded carrier panels, recommendations related to interpretation of molecular findings, as well as needs for further data collection and research.

This paper: (a) reflects on these new challenges in the context of lessons learnt from several decades of population-based carrier screening, (b) contributes to the public and professional discussion on expanded carrier screening, (c) contributes to the development of clinical and laboratory guidelines, and (d) provides recommendations for health care policy and professionals. The paper was prepared by members of the PPPC of the ESHG and recommendations were posted on the ESHG website from 4 February 2015 to 15 March 2015, for membership consultation and comments from external experts. The final version was approved by the ESHG Board on 6 September 2015, and also endorsed by the BSGM Board. This document starts with an outline of attitudes of health care professionals and the public towards carrier screening, followed by an overview of carrier tests currently available and discussed against the Analytic validity, Clinical validity, Clinical utility, Ethical, legal and social implications (ACCE) Framework, and ends with (consensus) recommendations.

\section{Summary points (I)}

- The primary goal of carrier screening is to facilitate informed reproductive decision making by identifying those couples at risk of having an affected child with an (autosomal or X-linked) recessive disorder.

- Expanded carrier screening offers carrier screening for multiple recessive disorders, facilitated by new genetic testing technologies that enable the expansion of screening without significantly higher costs. An increasing number of commercial laboratories already offer expanded carrier screening.

- Expanded carrier screening allows testing of all individuals regardless of ancestry or geographic origin ('pan-ethnic' or 'universal'), which in this respect increases equity and reduces the chance of stigmatization. Responsible implementation of expanded genetic carrier screening, however, raises many technical, ethical, legal and social questions.

- The best time to offer screening is during the preconception period, since identifying carrier couples before pregnancy allows the greatest number of options with more time to make an informed decision. Efforts should be made to facilitate this timing.

\section{ATTITUDES OF HEALTH CARE PROFESSIONALS AND THE PUBLIC}

The attitudes and perceived barriers, and concerns among health care professionals and the general public towards carrier screening for specific genetic disorders have been well researched. However, it is difficult to know how or whether these findings extrapolate to expanded carrier screening: Some findings may be removed or reduced, while new issues may arise, as we will discuss.

\section{Health care professionals' attitudes and perceptions}

The positive attitude of potential providers is vital to the success of a screening programme. The attitudes and perceptions of health care providers towards carrier screening have been studied primarily for individual genetic disorders, especially for CF and haemoglobinopathies (HBPs; sickle cell disease and thalassaemia). Generally there is a positive attitude towards carrier screening, ${ }^{18}$ however, several concerns and barriers exist including the psychological impact of screening, lack of knowledge, lack of guidance and costs. Sufficient pre- and post-test education and counselling have an important role in limiting the possible negative psychological effects of carrier screening, since improved genetic knowledge is inversely correlated with the testee's anxiety. ${ }^{19}$ A lack of knowledge/adequate education among both professionals and the lay public has been a major concern among health care professionals in many surveys. ${ }^{20-23}$ In addition, lack of time to offer screening and counselling has been mentioned as an important barrier..$^{22,24,25}$ Additional barriers are prohibitive costs (or lack of reimbursement), lack of supporting services, ${ }^{21,22,26}$ and lack of awareness of (or use of) existing guidelines. ${ }^{20,21,27}$ That said, many countries have no clear guidelines or policies for carrier screening, and testing is only offered at a local level, or as pilot projects, resulting in very few health care professionals providing screening to their patients. For example, in the Netherlands, the lack of a national policy was seen as a major barrier to offering carrier screening for HBPs. ${ }^{28}$ Even in countries where guidelines do exist, for example, in the United Kingdom, service delivery was initially poor or patchy. ${ }^{29}$ In the United States several ACMG/ACOG recommendations on carrier screening for different disorders exist and are frequently updated. For example, the ACOG launched CF carrier screening guidance in 2001. However, a decade later a concerning percentage of obstetricians are still ignorant about their existence. ${ }^{20}$

In 2012, experiences and opinions on expanded carrier screening for $>100$ diseases of variable severity were assessed among 222 gynaecologists and obstetricians in the United States. Although there may have been a bias towards those who are the most informed about the topic, $15 \%$ of the professionals offered expanded carrier screening to all patients, while $52.1 \%$ offered it upon a patient's request. ${ }^{30}$ The majority of respondents $(65.8 \%)$ in this study believed that the optimal time for expanded carrier screening was prior to conception. However, preconception carrier screening is considered less feasible by health care professionals, ${ }^{18,31}$ and evidence from carrier screening practice shows that it is mainly offered in pregnancy. ${ }^{20,21,31}$ In a focus group study by Cho et al..$^{32} 40$ genetics professionals stressed the importance of pre- and post-test counselling and opined that counselling should be provided by a clinician with expertise in communicating genetic information. Ready et $a l .{ }^{33}$ surveyed the attitudes regarding expanded genetic carrier screening among 203 health care providers, of whom $61 \%$ were physicians. This study indicated that the majority of participants believed that a post-test consultation with a genetic counsellor would be helpful (84\%), or indeed essential (78\%). Most people undergoing carrier screening will not be familiar with the conditions it can detect, so that many questions are likely to arise for carrier individuals/couples, and may require referral to other health care professionals who can answer these. Screening for multiple diseases could thereby act as drivers to refer patients with abnormal screening results to a genetic service, resulting in significant service pressures. New service models could be developed with genetic counsellors working more closely with primary care providers and telemedicine genetic counselling (ie, medical information exchange via electronic communication, for example using a real time video link). Cho et al. ${ }^{32}$ also highlighted concerns that expanded carrier screening could not fully rule out the possibility of severe recessive diseases since rare sequence variants would not be detected, thus resulting in 'false reassurance' about reproductive risks 
with negative results. Some participants felt that selective panels would be more appropriate for some people belonging to high-risk groups.

Potential providers of expanded carrier screening cite the (likely) lower costs as a major advantage over conventional (single gene sequence variants) screening and despite their concerns about the technical limitations of expanded carrier screening, genetic professionals considered the possibility of widening the range of sequence variants without significant increases in the cost to be an advantage. ${ }^{32}$ It is important to note, however, that the true costs of expanded carrier screening includes follow-up counselling needs and investigations and these are not included in marketing claims of lower costs. ${ }^{34}$ Future research could usefully investigate the additional costs, and the competences and education required for expanded carrier screening. The capacity of the health care system (and in particular of the genetics professionals) to deal with information and counselling, as well as downstream services demands, should be properly evaluated up front before decisions regarding implementation are taken.

\section{Public attitudes}

The identification of the gene causing CF in 1989 was followed by extensive research on public attitudes with regard to carrier screening for this disorder. A recent systematic review summarising 23 years of research shows strong support among the public: The majority of people (range 60-100\%) believe CF carrier screening should be available, while $80-96 \%$ believe that it should be routinely offered. ${ }^{35}$ Most - like health care professionals - thought the best time to offer it would be prior to conception. ${ }^{35,36}$ The highest interest in carrier screening was observed among people of reproductive age, in particular if they had no children at the time of the survey. ${ }^{37}$ Previous studies have shown that the majority of parents of a CF child and adult patients also support population carrier screening ${ }^{38-40}$ and only a minority of parents and patients feel that testing should be restricted to families with a family history of the disease. ${ }^{38}$ Some fear, however, that the expansion of screening to more diseases may lead to greater feelings of guilt and blame surrounding a potentially avoidable disorder. ${ }^{41}$

In some genetically isolated communities, carrier screening is a well-known and well-accepted practice. ${ }^{42-45}$ Positive attitudes in the AJ population have been reported, not only towards carrier screening in adults (eg, in the context of a premarital confidential carrier matching programme for ultra-orthodox - Dor Yeshorim programme- ${ }^{46}$ or offered more openly), ${ }^{47}$ but also towards screening adolescents in high schools. ${ }^{48,49}$ Starting in the 1970s with the offer of screening for Tay-Sachs Disease (TSD), carrier screening in this community has already expanded to include many more diseases. ${ }^{50,51}$ Due to founder effect, the AJ population is at increased risk for several specific recessively inherited diseases, sometimes referred to as 'Ashkenazi Jewish Diseases' ${ }^{50}$ The attention that it has been given may have led to a higher sense of vulnerability in this population and thus more interest in testing for multiple diseases compared with the general population. ${ }^{50,52}$ Members of this community generally accept a screening offer, even for diseases with lower carrier frequencies and/or detectability, ${ }^{51}$ and also if the disease in question is relatively mild. ${ }^{50}$ In particular, this last issue has already created lively discussions. ${ }^{53,54}$ The expansion of carrier screening to other diseases may, in part, be driven by the demand of the AJ population. ${ }^{51}$ A survey study among 145 individuals of the Dutch Jewish community showed that $56.6 \%$ agreed that a carrier screening offer should include all diseases couples want to be tested for. ${ }^{55}$ In this study, no convincing preference for ancestry-based or pan-ethnic carrier screening was shown. The most important reason to prefer an ancestry-based panel was to prevent high health care costs. As costs of expanded carrier screening panels are most likely to drop in the future, it is expected that these expanded panels will receive more support in the future.

In some countries where a severe recessive disorder is common, the severity of the disease has led to successful screening strategies, in terms of high uptake and awareness. For example, beta-thalassaemia carrier screening has a long and successful history in several at-risk populations in the Mediterranean area. ${ }^{56}$ In some European countries, disorders that were previously uncommon have now become much more frequent due to global migration. For example, the prevalence of HBPs (sickle cell disease and thalassaemia) has risen in Northern Europe due to the increased number of immigrants from Africa and Mediterranean regions. Studies have shown that migrant populations in countries such as the United Kingdom and the Netherlands have positive attitudes towards screening for these disorders, although acceptance of reproductive options, such as prenatal testing and termination of affected pregnancies, may be low among particular groups. ${ }^{29,57-62}$

A limited number of studies have addressed attitudes towards screening for other conditions, such as spinal muscular atrophy ${ }^{63}$ and Fragile X syndrome, ${ }^{64-66}$ and despite the heterogeneous phenotype and complicated inheritance of the latter, similar positive attitudes have been found. More research is needed to assess general public perceptions about the benefits and barriers to expanded carrier screening panels.

\section{Uptake}

In countries where carrier screening programmes aim to enhance reproductive decision making for couples at risk for a disease, helping and empowering couples to make an informed choice is considered a prerequisite for a successful programme. Here uptake per se is considered of less importance, while the harder-to-measure autonomous decision making that testing facilitates is the key concept. The effectiveness of a screening programme should ideally be assessed in terms of a measure of informed choice. ${ }^{67}$ This implies that the decision to accept or decline screening must be based on relevant knowledge, free of coercion from others and consistent with the decision-maker's values. Insight into the factors that influence uptake, and the reasons why individuals or couples decide to have a test or not might indicate the degree of informed choice.

Population-based carrier screening for CF has mainly been offered during pregnancy, in particular to women attending a routine antenatal clinic visit, where uptake rates of $46-99 \%$ have been reported. ${ }^{35}$ In contrast, despite the overall positive attitudes of the general public, the uptake rate of any form of preconception screening is much lower, even when screening is offered free of charge. ${ }^{62,68,69}$ Whether these findings reflect a greater interest in screening among pregnant women or simply represent an easier point at which to offer screening (eg, because blood samples have often already been taken at time of offer, and tests in pregnancy are generally regarded as important) is not clear. The method of invitation is also important for CF carrier screening uptake: measured to be $\sim 10 \%$ when invitations were sent by letter, yet $25-87 \%$ with active opportunistic testing, that is, a personal approach and immediate possibility for testing. ${ }^{31,70}$ This could reflect supply push rather than population demand but there is inevitably also a relationship between the two. ${ }^{71}$ When carrier screening is offered alongside other tests, informed decisions may in fact be compromised. A reflection period to decide whether or not to have the test would give people the opportunity to 
make a decision based on the perceived benefits and not just because it is offered. ${ }^{70}$ In contrast, the low uptake rate achieved by mailed invitations might be due to other reasons such as lack of knowledge and perceived barriers (eg, inconvenience of the time or location for having the test). ${ }^{37,68,69}$ Other factors also influence the uptake of screening, again most extensively studied for CF. ${ }^{35,37}$ Besides factors related to individual characteristics (eg, education) and perceptions (eg, of the benefits and barriers of screening) factors related to the quality of delivery of genetic services, carrier testing information and counselling also influence the screening uptake. For example, the low uptake of HBPs carrier testing among immigrants in the United Kingdom was partly due to a lack of knowledge among physicians about the diseases, misconceptions about the immigrants' norms and values, ${ }^{72}$ and offering a test late in pregnancy. ${ }^{73}$ Evidence about the types of interventions that could improve informed decision making about screening is limited and further research into these deserves priority, especially in disadvantaged groups. ${ }^{74}$

Would expanded screening influence uptake? It is likely that individuals and couples who would not consider any of the reproductive options arising as a result of carrier screening (eg, termination of pregnancy, using donor gametes or choosing another partner), will neither be interested in having expanded screening. For some, offering screening for more than one disease may increase the perceived benefits of testing (greater chance of finding that they are a carrier couple) and such couples may be more willing to participate. Expanding carrier screening in AJ high schools from one disease (TSD) to seven diseases resulted in an increase in uptake. ${ }^{19}$ The authors, however, concluded that another variable - the use of cheek brush swabs instead of taking blood samples for DNA extraction may also explain this increase. ${ }^{19}$ The need for blood tests is cited as a barrier by people who declined screening, especially in high school screening programmes. ${ }^{37}$ More research is needed on how uptake is affected by the expansion of panels and whether individuals and couples can make informed decisions with respect to such an offer.

\section{REPRODUCTIVE DECISION MAKING}

With regard to CF carrier screening, a recent review has demonstrated that $80-100 \%$ of the carrier couples identified through primarily prenatal screening, decided to have prenatal diagnosis to find out if their unborn child had $\mathrm{CF}^{35}$ Once confirmed, termination of pregnancy was undertaken for almost all of the affected fetuses. Less is known about prospective carrier couples identified preconceptionally as much longer follow-up is needed to assess their subsequent reproductive decisions. While improving informed reproductive choice is considered as the primary goal of screening, this may also have as a consequence, although it is not the primary aim, that the birth prevalence will be reduced. Expanded carrier screening may result in more couples deciding to have prenatal diagnosis or preimplantation genetic diagnosis, abstain from children or use donor gametes, and thus as a consequence, may lead to a reduction in the number of children born with the diseases that are screened for.

In communities with high frequency of carrier status and a high disease burden, and where carrier screening is common, uptake rates are also very high. A resultant decline in births of children with the disease in question has been observed. For example, a 90\% reduction of children born with TSD was observed in the AJ community as a result of carrier screening, followed by prenatal diagnosis when indicated. ${ }^{10}$ But in this community, the reduction of the burden of disease or prevention is also regarded as an explicit aim of screening and well-accepted by the community. ${ }^{9}$ In Cyprus, both in the republic of Cyprus and Northern Cyprus, carrier screening for beta-thalassaemia, initially a mandatory programme to actively discourage marriage between carriers of thalassaemia, has resulted in a decrease of the birth prevalence by more than $95 \% .{ }^{27}$ Similar results were found in Sardinia ${ }^{56}$ and Turkey. ${ }^{75}$ In Turkey, the Haemoglobinopathy Control Programme was initiated issuing a law in 1993 and starting (especially premarital) screening in high-risk provinces. ${ }^{76}$ Since 2003, it has been offered more widely, accompanied by an extensive public eduational programme. ${ }^{75}$ In other countries, such as Iran, Bahrain and Saudi Arabia, (mandatory) premarital screening programmes have become widely accepted; ${ }^{27}$ some of these programmes clearly mention prevention as their aim. ${ }^{77}$ However, these programmes have not necessarily led to a reduction of affected births in the related countries as a consequence of several factors, including couples who marry despite being diagnosed as carrier couples and prenatal diagnosis not being available or offered. ${ }^{77-79}$

\section{Summary points (II)}

- Research among health care providers has identified the following challenges to the implementation of carrier screening programmes: low genetic literacy among patients and medical practitioners, costs and reimbursement issues, variability among different national health services and regional health systems as well as lack of or limited use of professional guidelines.

- Attitudes towards the offering of carrier screening among the general public were found to be overwhelmingly positive. The actual uptake of carrier screening, however, varies greatly among countries and communities. The uptake is highest in some Middle Eastern and Mediterranean regions, where screening (for betathalassemia) is mandatory. In addition, some ethnic groups, such as Ashkenazi Jewish communities, have traditionally been highly receptive to carrier screening for recessive conditions.

- Carrier screening programmes aiming to enhance reproductive decision making for couples should include in its evaluation a measure of informed choice.

\section{THE CARRIER SCREENING TEST}

Although rapidly evolving genomic technologies facilitate carrier screening for a growing number of diseases simultaneously, developing a screening panel which meets the criteria that justify screening, including known positive and negative predictive values for each test, remains a challenge. One of the frameworks to assess new emerging tests is the ACCE framework developed by the Centers for Disease Control and Prevention (CDC, Atlanta, GA, USA), National Office of Public Health and the Foundation of Blood Research (http://www.cdc. gov/genomics/gtesting/ACCE/; last accessed 18 August 2015).

\section{Analytic validity}

Analytic validity of a genetic test defines its ability to accurately and reliably measure the genotype of interest. Current commercial providers use mostly microarray-based genetic tests covering most frequent sequence variants in selected genes. Although the results may differ between providers, it has been shown that the validity of microarray test results is comparable to blood-based single-gene carrier tests. ${ }^{80}$ Alternatively, whole genes, and not only selected sequence variants, can be enriched and sequenced by nextgeneration sequencing (NGS). ${ }^{81}$ Analytical validity of targeted NGS is comparable to Sanger sequencing, ${ }^{82}$ while concordance and sensitivity of whole-exome and whole-genome sequencing was reported to exceed 97 and 95\% compared with high-density microarrays; main sources of non-uniformity included variance 
in depth of coverage, artefactual variants resulting from repetitive regions and larger structural variants. ${ }^{83}$ Clinical use of NGS is still in its early phase and recommendations are being developed for assuring the quality of NGS in clinical laboratories; ${ }^{84,85}$ nevertheless, it is expected that companies start moving to NGS for their expanded panels. For certain conditions, such as HBPs and TaySachs disease, biochemical methods may provide better accuracy than molecular methods. ${ }^{11}$

\section{Clinical validity}

Clinical validity of a genetic test defines its ability to detect or predict the associated disorder, or in our case carrier status. It is described in terms of sensitivity, specificity, positive and negative predictive values and is influenced by the prevalence of the tested disorder or carrier state, penetrance and genetic or environmental modifiers. Most genetic disorders are characterised by allelic heterogeneity, which means that more than one sequence variant in a given gene is associated with the phenotype. For example, more than 2000 sequence variants have been reported in the CFTR gene associated with CF (http://www.genet.sickkids.on.ca/StatisticsPage.html; last accessed 18 August 2015). The most common sequence variant p.Phe508del in CF patients demonstrates a significant population specific distribution with decreasing prevalence from Northwest to Southeast Europe, and fewer than 20 sequence variants occur at a worldwide frequency of more than $0.1 \%$. On average, commercial providers of carrier testing only test a small number of all known sequence variants in a particular gene, while the average number of sequence variants associated with genes included in the panel according to the Human Genetic Mutation Database (HGMD) is 284 per gene (http://www.hgmd.cf.ac.uk/ac/ index.php; last accessed 11 August 2014). ${ }^{86}$ Furthermore, several sequence variants are very rare or associated with a milder or variable phenotype, however, data on the exact molecular pathology (frequency of variants in a certain gene or proportion of variants in different genes if genetic heterogeneity is present) for a given genetic disorder in different populations are still often not available. As the carrier screening panels are fixed in the microarray based testing and focused to a limited number of sequence variants, they cannot comprehensively address the molecular pathology in diverse populations ('pan-ethnic' setting), neither the spectrum of tested genes nor the spectrum of sequence variants.

All these factors, (population specific molecular pathology and number of sequence variants and genes tested per genetic disorder) affect the clinical sensitivity (proportion of the carriers identified if a tested person is a carrier) of the test as well as the negative clinical predictive value (probability that the tested person is not a carrier if the test is negative) and varies depending on variant frequency in a particular population. NGS approaches have the potential to increase clinical sensitivity ${ }^{81,87}$ since several thousands of variants are tested in one diagnostic assay. NGS testing may be bioinformatically limited to the variants, known to affect function or designed to detect new sequence variants as well. In the latter case, a NGS approach will at times also generate variants of as yet unknown significance as well as potential incidental or unexpected findings. NGS approaches may be based on target enrichment methodology including coverage of the exonic, intronic and regulatory regions. Alternatively, if exome sequencing is used as the NGS approach, sequence variants in several intronic and regulatory regions might remain undetected. Furthermore, certain exonic regions do not yield enough sequencing data to make high-quality genotype detection possible. The positive predictive value, the chance of developing the disease if the test is positive, will be different for different disorders as a function of the penetrance and expressivity of different sequence variants. This also means that a given variant may be associated with different clinical severity or disease manifestation even in the same family. For prospective carrier couples, the prediction of the phenotype in an affected child will be even more difficult based on the combination of the variants of both parents. The exact prevalence rate for recessive disorders worldwide is not known and is complicated by geographic or population variability. A systematic survey of epidemiological data in Europe is offered by Orphanet, ${ }^{88}$ but information is not population specific. Bell et al. ${ }^{81}$ have shown that the average carrier burden of severe childhood-onset recessive disorders after screening for 448 genes in 104 unrelated samples was 2.8 (range $0-7$ ). A screening panel of 108 disorders and 417 disease causing variants identified $24 \%$ of individuals as carriers for at least one variant. ${ }^{89}$ On the other hand, the Genome of the Netherlands Project demonstrated a high frequency of some of the HGMD variants that affect function associated with autosomal recessive disorders in the healthy Dutch population. ${ }^{90}$ In fact, many tested individuals carrying two copies of the allelic variant should have been affected by diseases which implies a considerable number of false positive disease-causing variants in the $\mathrm{HGMD}^{81,91}$ (or potentially other mutation databases), incomplete penetrance/variable expressivity of variants, or both. Consequently, clinical validity of carrier screening might be uncertain for several variants, presently considered as disease-causing.

\section{Clinical utility}

The clinical utility of a genetic test refers to the value of the genetic information to medical practice and whether the test can significantly improve patient outcomes. For preconception carrier screening, clinical utility is the increase in a couple's reproductive autonomy and choice. In the future, preconception carrier screening might facilitate better perinatal diagnosis with early management of genetic disorders. Current commercial providers often market their genetic tests by highlighting the possibility of treatment either in pregnancy or after birth, even though hard evidence for this is lacking or clinical relevance is not clear from the selection of diseases in the screening panel. For example, haemochromatosis is often included in the panel, ${ }^{92}$ despite the lack of evidence of benefit in general population screening, let alone in reproductive planning. ${ }^{93,94}$ Phenylketonuria, which is included in the panels of most of the providers, is a treatable condition, although treatment (diet) may be challenging. It is associated with good prognosis as it is already diagnosed early in newborn screening programmes. For some treatable disorders, knowing that both parents are carriers could improve the prognosis if the diagnosis thereby can be made earlier, but this must be explained in the pre-test information. It is not unthinkable, though, that couples planning a pregnancy will consider requesting prenatal diagnosis or pre-implantation genetic diagnosis for these disorders. The lists of disorders included in the expanded carrier testing panels differ among test providers. There are differences in numbers and types of diseases, in the ages of onset (neonatal, childhood, adult life) and in treatability and severity. ${ }^{86}$

As previously mentioned, there are currently 1300 known recessive (autosomal and X-linked) diseases and about 100 of these have a prevalence of $>1 / 100000 .{ }^{88}$ Several important conditions, for example, Duchenne/Becker muscular dystrophy and Friedreich ataxia are not included in any of the commercial panels, presumably due to technological limitations of the microarray-based testing approach (eg, trinucleotide repeat mutations). We propose that, pending convincing evidence to the contrary, retaining a 'serious congenital and childhood onset disorders' scope is important in panel design. This is in line with 
the scope that was also proposed in a recent joint ESHG/ASHG document on non-invasive prenatal testing. ${ }^{95}$ As expressed in that document 'This can be justified in the light of the normative framework as providing women or couples with meaningful reproductive choices rather than with the (theoretical) option of receiving all information that genomic technologies can possibly reveal about the fetus.' There is no general agreement on classification of genetic disorders based on the severity of disease. ${ }^{96}$ Nevertheless, a systematic classification of disease severity in the context of expanded carrier screening has been recently proposed in a study described by Lazarin et al. ${ }^{97}$ based on health care professionals' opinion. Disease characteristics that scored highest in their study included shortened life span, intellectual disability, impaired mobility and internal physical malformation.

For some conditions carrier screening could also reveal increased risk of morbidity for potential carriers. For example, heterozygous carriers for sequence variants in the glucocerebrosidase gene (included in several screening panels and related to autosomal recessive Gaucher disease) have a significantly increased risk of developing Parkinson's disease in later life. $^{98}$ Carriers of Ataxia Telangiectasia have an increased lifetime risk for breast cancer; and carriers of the Fragile $\mathrm{X}$ (FMR1) premutation have an increased risk of primary ovarian insufficiency and can develop a neurodegenerative disorder (Fragile X-associated Tremor/Ataxia Syndrome; FXTAS) in adulthood. ${ }^{99}$ In the future, more associations between carrier states and increased or decreased risks for diseases will likely be revealed, and these will increase the complexity of counselling for expanded carrier screening.

In addition to the impact for the individual or couple, identification of some sequence variants may have implications for the extended family members, leading to specific carrier testing and reproductive options. Therefore, potential clinical consequences in heterozygous carriers should be adequately covered in the provision of pre- and post-test information.

\section{Ethical, legal and (psycho)social issues}

The responsible introduction of expanded carrier screening requires a careful appraisal of the advantages and disadvantages for the target population. Among the advantages are the reproductive options that the offer of carrier screening might lead to. Nevertheless, it is also important to discuss some of the ethical, legal and (psycho)social concerns that might be connected to a carrier screening offer.

\section{Issues of autonomy and informed consent}

The introduction of genetic reproductive screening programmes in the general population raises many concerns about complex decisions such as prenatal diagnosis and selective termination of pregnancy. Although guidelines have emphasised the need for genetic screening to be voluntary, non-coerced and based on an informed choice, these concerns recognise the difficulties in implementing such guidance. Ensuring that individuals are aware of the purpose of the screening and the possible implications of the results (including understanding of the residual risk in a screen-negative result) will be increasingly difficult if more conditions with differential implications are included in a screening panel. ${ }^{13,14}$ Since the stated aim of reproductive screening (including carrier screening) here is not prevention, but rather the provision of options for reproductive decision making, appropriate pre-test information and voluntary decision making becomes an essential requirement rather than a mere side-constraint: without this, the screening cannot fulfil its aim.

Gaining valid consent has been considered much more challenging the more carrier screening panels expand. As a result of information overload', this may paradoxically undermine rather than serve the very aim of providing options for meaningful reproductive choice. ${ }^{100}$ Suggested ways around this include the development of uniform and coherent panels. Elias and Annas ${ }^{101}$ proposed the concept of generic consent as a way to safeguard informed decision making in situations where information overload is threatening. In this approach, prospective testees would be generally informed about types of possible test outcomes and implications. ${ }^{102}$ They would be told that the procedure is carried out to identify individuals/couples, for example, at an elevated risk of having a child with a severe disability. Some of these diseases, as well as associated clinical symptoms, can be briefly mentioned as illustrative examples. The limitations of the test, such as the possibility of false positive and false negative results, should be included in such generic consent. For those couples identified as carriers, more detailed follow-up counselling would be important. ${ }^{101}$ Recently, the ACMG acknowledged the advantages of generic consent in the context of expanded carrier screening. In a policy paper published in June 2013 it is stated that: 'A highly multiplex approach will require a more generic consent process than is typically used for single-disease screening because it may not be practical for a clinician to discuss each disease included in multi-disease carrier screening panels' ${ }^{17}$ Such consent comes with some concerns: less detailed information could lead to less informed decisions, ${ }^{103}$ and the type of information may need to be adapted for specific groups. In contrast, some individuals might require more specific and in-depth information to make a decision regarding screening. ${ }^{101}$ In order to meet the needs of individuals seeking in-depth understanding of the carrier screening procedure, usage of appropriately tailored information pamphlets, websites and other audio-visual aids might be useful. Tailoring of modern technologies, for example, smart-phone apps, could help to ensure that all interested patients can make informed choices about carrier screening programmes.

\section{Individual and community impact}

Learning about carrier status by participating in a carrier screening programme could impact on: (1) psychological well-being, (2) perceptions of health and (3) (feelings of) discrimination or stigmatisation (social consequences).

Impact on psychological well-being. Studies have demonstrated increased distress levels among carriers, but most are not clinically significant and/or levels return to normal shortly after. ${ }^{104-106}$ When screening is offered to couples, taking a sample from both partners at the same time prevents the anxiety and the need for counselling that might arise among those who are tested positive while the other partner is asked to provide a sample to be tested. ${ }^{107}$ Sampling one partner later can also be harder to organise. As more disorders are added to screening panels, the chance of being a carrier of something, or being a carrier couple, increases. Couple-based disclosure - where a result is only positive if both members carry the same condition - would reduce anxiety in a $+/$-couple (ie, one partner tests positive while the other tests negative), since they would receive an overall negative result. ${ }^{108}$ However, this means that individual carriers are not notified, so that a test would have to be repeated with a new partner, and informing relatives would happen in fewer cases.

In a study evaluating a carrier screening programme in high schools for the AJ population in Australia, it was shown that expanding the screening from one disease (TSD) to six increased the number of students who anticipated negative feelings if found to be a carrier of one of the conditions. ${ }^{19}$ Considering that in an expanded carrier 
screening programme many (rare) autosomal recessive disorders but also X-linked disorders will be included, the potential psychological impact could increase, as this will also allow to identify carriers of multiple recessive conditions. The possibility of psychological harms could be minimised by educating prospective test-takers about the screening programme, and about the implications of being a carrier. For example, a (still ongoing) Australian study screening for Fragile X syndrome carriers showed minimal impact, possibly also due to intensive counselling and women given the opportunity to deliberate their decision to screen. ${ }^{109}$ In contrast, carrier screening for betathalassaemia in Australia occurs with every pregnant woman in a very ad hoc fashion (ie, through initial full blood examination) with little (if any) pre-test counselling and also minimal education even post test. ${ }^{110}$ Consequently, thalassaemia carriers often misunderstand their status. ${ }^{111}$ As testing becomes more common people will become aware that all individuals are carriers for a limited number of sequence variants and this may decrease anxiety. Efforts should be undertaken to promote programmes that enhance genetic knowledge of the public.

Impact on perceptions of health. Some earlier studies have described less optimistic health perceptions after receiving positive test results, ${ }^{104,112,113}$ although others have found no impact of screening on health perceptions. ${ }^{114,115}$ In a 3-year follow-up study on prenatal carrier screening for CF there was a small negative effect on how carriers perceived their current health. ${ }^{104}$ Similarly, in a preconception $\mathrm{CF}$ carrier screening programme it was found that carriers perceived themselves as less healthy. ${ }^{113}$ Several explanations, such as reduced optimism of carriers about their health and poor understanding of the test results, have been suggested for this finding. ${ }^{112}$ Expanding screening to more diseases may increase the misconceptions about health status of carriers and induce more anxiety. ${ }^{19}$ This may be complicated by the overall limited public (and professional) knowledge of genetics and lack of awareness of genetic diseases.

Stigmatisation and discrimination. Stigmatisation is the effect of labelling a group or person with negative social or psychological characteristics. Stigmatisation of carriers within the community is one concern that has been described, for example, with regard to the orthodox Jewish premarital screening programme Dor Yeshorim., ${ }^{9,116}$ Moreover, some genetic diseases are more prevalent in certain groups based on ancestry. Therefore, members of a particular group or subpopulation may be or feel stigmatised or discriminated against as a result of carrier status information. Encouragingly recent studies have revealed no predominant feelings of discrimination or social stigma among carriers, but in the 1970s, screening programmes for sickle cell disease resulted in misunderstanding of carrier status; fear and widespread discrimination and stigmatisation of African-American carriers, and insurance companies refused health and life insurance to sickle cell carriers as a result of their own misinformation. ${ }^{117}$ Similar findings have been reported from other earlier screening programmes. ${ }^{118}$ One way to minimise these issues is to improve community education and public campaigns and appropriate information and counselling. Moreover, it has been suggested that addressing the whole population for screening but using a decisional aid to determine the risk of disease, and thus eligibility for testing as a selection from particular disorders, based on ancestral background might avoid stigma, ${ }^{119}$ especially if almost any couple would be eligible for some form of testing. Increased intermarriage, however, complicates delineation of who is at risk. Expanded carrier screening might, in fact, decrease stigmatisation as screening could be offered as a 'universal test' rather than targeted to a particular subpopulation.

Concerns have been raised that carrier detection devalues the lives of affected patients or impedes the search for a cure because they are seen to be associated with encouraging a reduced birth prevalence of affected children. Other concerns about carrier screening include confidentiality of test results and fear of undue pressure on individual choice $^{15}$ in particular in socially tight communities 9 or schools. 'Peer pressure' has been reported as a reason to participate in high-school carrier screening, ${ }^{49}$ although a study offering hereditary haemochromatosis in the high-school setting showed that $<1 \%$ of the students indicated that the decisions of their friends/peers influenced their participation in screening. ${ }^{120}$

Equity and fairness. Although the introduction of expanded screening universally offered to the whole population regardless of ancestry can be regarded as increasing equity (access for everyone), a justice concern is that those who might profit most may be less well helped by that offer. First, a universal offer may undermine the awareness of risk among those in higher risk groups. Second, because universal screening panels may cover a lower number of sequence variants than would be considered appropriate in an ancestry-based screening offer, there would still be a need to target those groups separately, which raises logistical complexities. When considering universal carrier screening, providers and health authorities should be aware of these possible drawbacks and make sure that services are in place to avoid unfair treatment of those at the highest risk.

False reassurance. For people who are found to not carry a disease allele after screening, it is important that the different aspects of screening are well understood. A negative (favourable) carrier test result, received by the majority of those screened, may result in relief among participants. Previous studies have demonstrated that this may, however, also result in a false sense of security (false reassurance), as a considerable number of people who receive a screen-negative result mistakenly believe that they are definitely not carriers. ${ }^{19,104,113}$ As most carrier screening tests still convey a small residual risk - mostly due to incomplete sensitivity of the test - after a favourable test result (if one partner or even both partners are negatively tested) these couples may thus be confronted with the unexpected birth of a child with the disease. Furthermore, many pregnancy risks other than recessive diseases have not been included. Health care professionals thus need to address potential misperceptions that expanded carrier screening can guarantee a healthy child.

Conversely, couples may take far-reaching reproductive decisions (eg, refraining form having children) that might not have been needed, either because of a lack of understanding of test-results or because panels are unsufficiently validated.

\section{Commercial offers}

The development of expanded carrier screening has until now been largely stimulated by commercial offers, often directly to consumers. On the one hand broader access to genetic testing services directly to the consumer might enhance their reproductive autonomy, on the other it might also raise concerns due to the absence or uncertain quality of pre- and post-test information, counselling and/or medical supervision. ${ }^{92}$ Moreover, as noted earlier, various concerns exist about the conditions included in various panels (eg, mild diseases) as well as the inclusion of variants of unknown significance or variants that are not clearly pathogenic. Finally, commercial offers might lead to an increased burden on public health resources due to an increased call 
on primary care physicians, clinical genetic services or other health care professionals for more information or counselling.

\section{Summary points (III)}

- Currently the commercial offer of expanded carrier testing is of limited clinica validity in terms of reproductive carrier screening, especially where it includes diseases that are not considered severe or have onset in adulthood (in which case they should not be offered for the purpose of facilitating reproductive decisions).

- Carrier screening may reveal clinically relevant disease risk for a screened individual.

- Expanded carrier screening will lead to the detection of more carriers and carrier couples. Generally there is no lasting negative effect of carrier status on anxiety, self-concept or stigma, although false reassurance for some needs to be taken into account.

- Gaining valid consent is much more challenging, as well as time-consuming, the more carrier screening panels expand and may require new models of consent (eg, generic consent).

\section{CONCLUSION AND RECOMMENDATIONS}

Obviously, carrier screening for single-gene disorders is not new; however, the screening naturally expands as the range of disorders included in the screening expands; the pick up of 'carrier couples' is much greater as more conditions, genes and sequence variants can be screened for simultaneously than hitherto possible. By summarising the knowledge gained from several decades of population-based carrier screening, the aim of this document is to contribute to the public and professional discussion on expanded carrier screening, in order to provide recommendations for health care professionals, laboratory experts and health authorities. In discussing responsible implementation of carrier screening, an adequate and proportional balance of advantages and disadvantages should be achieved. Carrier screening is defined here as the detection of carrier status in couples or individuals who do not have an a priori increased risk for having a child with a certain disease based on their own or their partner's personal and/or family medical history. The introduction of new technologies, such as NGS, provides opportunities for expanded carrier screening panels for multiple autosomal and X-linked recessive disorders. Expanded carrier screening allows testing of all individuals regardless of ancestry or geographic origin. In order to minimise potential adverse psychosocial impact of carrier tests and ensure quality of tests, it is advised that such tests should comply with quality control and information standards, irrespective of whether they are offered through the national health care systems or through commercial companies. ${ }^{121}$ Research into the financial aspects of introducing expanded carrier screening into public health systems is needed. New funding models facilitating a participatory model (private payment of tests) and access to high-quality public sector facilities should also be explored.

On the basis of the evidence reviewed in this paper, the following recommendations are made:

1. Primary purpose of carrier screening: The primary objective of carrier screening in individuals or couples without a known family risk of recessive disorders should be to inform them of possible genetic disease risks in future offspring and of the reproductive options available in order to enable autonomous choices.

2. Expanded carrier screening: In line with the primary purpose, priority should be given to carrier screening panels that include (a comprehensive set of) severe childhood-onset disorders. Tests should be designed to achieve high clinical validity (clinical sensitivity, negative and positive predictive values) and should have established clinical utility. The main focus should be on reporting sequence variants that clearly affect function (with clear clinical significance).

3. Evidence: Before initiating expanded carrier screening it is necessary to establish an acceptable evidence base that should be continuously developed and solidified while screening takes place. This includes evidence about the significance of the screened sequence variants, the sensitivity and specificity of the tests, the immediate and downstream costs related to the test and screening offer, the psychological and social impact of a carrier screening offer, the types of interventions that could improve informed decision making as well as the public acceptability of carrier screening. More information on rare cases where carriers are affected to some degree is needed.

4. Timing of carrier screening: Expanded carrier screening should ideally be offered preconceptionally as this maximises reproductive options (and thus increases reproductive autonomy) and has fewer time constraints, resulting in less emotional distress than when a test is performed during pregnancy.

5. Reproductive decision making: As the primary objective is to strengthen reproductive choices and decision making of couples, the effectiveness of carrier screening programmes should be measured by assessing the extent to which it optimises informed choice and reproductive decision making and not by demonstrating how much it reduces the birth prevalence of affected children. This requires good follow-up information of those taking part.

6. Information and support: Expanded carrier screening will lead to the detection of more carrier couples (as well as more couples in which one partner tests positive while the other tests negative). Attention should therefore be given to psychological, social and counselling-related aspects, including explaining the reproductive options, potential consequences for relatives and the limitations of carrier screening such as the residual risk in a screen-negative result or interpretation of the functional impact of sequence variants. Psychosocial support and pre-and post-test information should be available (with test results provided in a timely and sensitive manner). Post-test clinical genetic counselling should be available and offered by genetic professionals to all carrier couples. Individual pre-test genetic counselling should be made available for those who request it. Given that this offer is to be provided to individuals (or couples) with an initial low risk and limited awareness of the disorders screened for, it is important to inform the public properly about these disorders and the various aspects of carrier screening. This may be achieved using different methods including media, leaflets and programmes in schools.

7. Informed consent: In the context of screening for multiple genetic disorders, the challenge is to adequately inform couples at the pretest stage about the goal, concept and implications of carrier screening, without having to explain every disorder to be screened for individually, as that would be impossible with expanding panels. Although new models of consent (eg, 'generic consent') have been proposed to meet this challenge, their introduction in this context requires evaluation, in order to explore whether this leads to couples making well-informed decisions about whether or not to accept the screening offer. Potential clinical consequences in heterozygous carriers should be adequately covered in the provision of genetic information and in the informed consent before testing. 
8. Voluntary participation: Decisions to have expanded carrier screening should be voluntary and informed: Individuals or couples should be sufficiently informed of the benefits, disadvantages and limitations of the screening test, and consent should be freely given with sufficient time to decide; there should be equity of access to testing services.

9. Quality of services: Genetic testing, as well as the provision of genetic information and counselling, should be provided by accredited genetic services and appropriately trained professionals.

10. Maximising quality of care: It should be made explicit to those receiving expanded carrier screening that care will continue to be provided to them regardless of their reproductive choices. In some cases, carrier screening could also contribute to the identification of disorders that might lead to early therapeutic procedures in affected offspring. This information should be adequately presented to couples. The availability of carrier screening should not be used as a rationale for reducing the quality of care available for children born with disease: standards of care should be safeguarded.

11. Professionals and public education and dialogue: Health care professionals involved in the provision of expanded carrier screening should receive appropriate education and training. Public understanding of genetics and carrier screening, including the benefits and limitations needs to be strengthened, recognising that the perception of the harms and benefits of screening is very different among different stakeholders. For this reason, it is important to have an open dialogue about the expected benefits and harms with all stakeholders, including patients and their representatives and the general public. This would enable key frameworks to be developed, in order to support informed decision making.

12. Governance: Governments and public health authorities should adopt an active role in discussing the responsible introduction of expanded carrier screening. This entails developing an implementation plan, ensuring quality control also extending to the nonlaboratory aspects such as providing information and counselling, education of professionals, systematic evaluation of all aspects of the offer as well as promoting equity of access, and setting up a governance structure for responsible further innovation. Governments and public health authorities should also develop oversight on the quality of genetic testing services provided by commercial companies.

\section{CONFLICT OF INTEREST}

$\mathrm{LH}, \mathrm{MC}, \mathrm{CvE}$ and PL are affiliated to a hospital that offers CF carrier screening on their website. SAM is affiliated to a genetics service that offers CF, SMA and FXS carrier screening on their website. The remaining authors declare no conflict of interest.

\section{ACKNOWLEDGEMENTS}

ESHG members and other experts are acknowledged for their helpful comments on an earlier draft of this document, in particular Carsten Bergmann, Jean-Jacques Cassiman, Angus Clarke, Gunnar Houge, Helena Kääriäinen, Leo P ten Kate, Neha Kumar, Gert Matthijs, Dragica Radojkovic, Maria Soller, Lisbeth Tranebjærg, members of the Dutch Working Group Preconception Carrier Screening, and members of the Italian Society of Human Genetics (SIGU). Grants for (implementation) research on carrier screening were received from The Netherlands Organisation for Health Research and Development (ZonMw) (LH, PL, WJD, GdW), Clinical Research Fund UZ Ghent (SJ, DC), the Research Fund Flanders (PB), National Health and Medical
Research Council, Victorian Government's Operational Infrastructure Support Programme, Shepherd Foundation, Helen MacPherson Smith Trust, the Apex Foundation and the Fragile X Alliance (SAM).

1 UNSCEAR (United Nations Scientific Committee on the Effects of Atomic Radiation): Hereditary effects of radiation. United Nations: New York, NY, USA, 2001.

2 Sankaranarayanan $\mathrm{K}$ : Ionizing radiation and genetic risks IX. Estimates of the frequencies of mendelian diseases and spontaneous mutation rates in human populations: a 1998 perspective. Mutat Res 1998; 411: 129-178.

3 Ropers HH: On the future of genetic risk assessment. J Community Genet 2012; 3: 229-236.

4 Morris JK, Law MR, Wald NJ: Is cascade testing a sensible method of screening a population for autosomal recessive disorders? Am J Med Genet A 2004; 128A: 271-275.

5 Henneman L, Borry P, Chokoshvili D et al: Responsible implementation of expanded carrier screening: Summary and recommendations of the European Society of Human Genetics. Eur J Hum Genet 2016; 24: 781-783.

6 Castellani C, Macek Jr M, Cassiman JJ et al: Benchmarks for cystic fibrosis carrier screening: a European consensus document. J Cyst Fibros 2010; 9: $165-178$.

7 Castellani C, Massie J: Newborn screening and carrier screening for cystic fibrosis: alternative or complementary? Eur Respir J 2014; 43: 20-23.

8 Rigter T, Henneman L, Kristoffersson $U$ et al: Reflecting on earlier experiences with unsolicited findings: points to consider for next-generation sequencing and informed consent in diagnostics. Hum Mutat 2013; 34: 1322-1328.

9 De Wert G, Dondorp W, Knoppers B: Preconception care and genetic risk: ethical issues. J Community Genet 2012; 3: 221-228.

10 Kaback MM: Population-based genetic screening for reproductive counseling: the Tay-Sachs disease model. Eur J Pediatr 2000; 159(Suppl 3): S192-S195.

11 Edwards JG, Feldman G, Goldberg J et al: Expanded carrier screening in reproductive medicine-points to consider: a joint statement of the american college of medical genetics and genomics, american college of obstetricians and gynecologists, national society of genetic counselors, perinatal quality foundation, and society for maternalfetal medicine. Obstet Gynecol 2015; 125: 653-662.

12 Andermann A, Blancquaert I, Beauchamp S, Dery V: Revisiting Wilson and Jungner in the genomic age: a review of screening criteria over the past 40 years. Bull World Health Organ 2008; 86: 317-319.

13 Nuffield Council on Bioethics: Genetic Screening. Ethical Issues. Nuffield Council on Bioethics: London, UK, 1993.

14 Health Council of the Netherlands: Committee Genetic Screening: Genetic Screening. Health Council: The Hague, The Netherlands, 1994, Report No. 1994: 22E.

15 Godard B, Ten Kate L, Evers-Kiebooms G, Ayme S: Population genetic screening programmes: principles, techniques, practices, and policies. Eur J Hum Genet 2003; 11(Suppl 2): S49-S87.

16 Human Genetics Commission: Increasing Options, Informing Choice: A Report on Preconception Genetic Testing and Screening. Human Genetics Commission: London, UK, 2011.

17 Grody WW, Thompson BH, Gregg AR et al: ACMG position statement on prenatal/ preconception expanded carrier screening. Genet Med 2013; 15: 482-483.

18 Janssens S, De Paepe A, Borry P: Attitudes of health care professionals toward carrier screening for cystic fibrosis. A review of the literature. J Community Genet 2014; 5: 13-29.

19 Ioannou L, Massie J, Lewis S et al: Evaluation of a multi-disease carrier screening programme in Ashkenazi Jewish high schools. Clin Genet 2010; 78: 21-31.

20 Darcy D, Tian L, Taylor J, Schrijver I: Cystic fibrosis carrier screening in obstetric clinical practice: knowledge, practices, and barriers, a decade after publication of screening guidelines. Genet Test Mol Biomarkers 2011; 15: 517-523.

21 Morgan MA, Driscoll DA, Mennuti MT, Schulkin J: Practice patterns of obstetriciangynecologists regarding preconception and prenatal screening for cystic fibrosis. Genet Med 2004; 6: 450-455.

22 Poppelaars FA, Henneman L, Ader HJ et al: How should preconceptional cystic fibrosis carrier screening be provided? Opinions of potential providers and the target population. Community Genet 2003; 6: 157-165.

23 Qureshi N, Armstrong S, Modell B: GPs' opinions of their role in prenatal genetic services: a cross-sectional survey. Fam Pract 2006; 23: 106-110.

24 Poppelaars FA, Van der Wal G, Braspenning JC et al: Possibilities and barriers in the implementation of a preconceptional screening programme for cystic fibrosis carriers: a focus group study. Public Health 2003; 117: 396-403.

25 McClaren BJ, Delatycki MB, Collins V, Metcalfe SA, Aitken M: "It is not in my world": an exploration of attitudes and influences associated with cystic fibrosis carrier screening. Eur J Hum Genet 2008; 16: 435-444.

26 Stark Z, Massie J, McClaren B et al: Current practice and attitudes of Australian obstetricians toward population-based carrier screening for inherited conditions. Twin Res Hum Genet 2013; 16: 601-607.

27 Cousens NE, Gaff CL, Metcalfe SA, Delatycki MB: Carrier screening for betathalassaemia: a review of international practice. Eur J Hum Genet 2010; 18: 1077-1083. 
28 Jans SM, De Jonge A, Henneman L, Cornel MC, Lagro-Janssen AL: Attitudes of general practitioners and midwives towards ethnicity-based haemoglobinopathy-carrier screening. Eur J Hum Genet 2012; 20: 1112-1117.

29 Modell B, Petrou M, Layton M et al: Audit of prenatal diagnosis for haemoglobin disorders in the United Kingdom: the first 20 years. Br Med J 1997; 315: 779-784

30 Benn $\mathrm{P}$, Chapman AR, Erickson $\mathrm{K}$ et al: Obstetricians and gynecologists' practice and opinions of expanded carrier testing and noninvasive prenatal testing. Prenat Diagn 2014; 34: 145-152.

31 Metcalfe SA: Carrier screening in preconception consultation in primary care. J Community Genet 2012; 3: 193-203.

32 Cho D, McGowan ML, Metcalfe J, Sharp RR: Expanded carrier screening in reproductive healthcare: perspectives from genetics professionals. Hum Reprod 2013; 28: 1725-1730.

33 Ready K, Haque IS, Srinivasan BS, Marshall JR: Knowledge and attitudes regarding expanded genetic carrier screening among women's healthcare providers. Fertil Steril 2012; 97: 407-413.

34 Stoll K, Resta R: Considering the cost of expanded carrier screening panels. Genet Med 2013; 15: 318-319.

35 Ioannou L, McClaren BJ, Massie J et al: Population-based carrier screening for cystic fibrosis: a systematic review of 23 years of research. Genet Med 2014; 16: 207-216.

36 Rowley PT, Loader S, Levenkron JC: Cystic fibrosis carrier population screening: a review. Genet Test 1997; 1: 53-59.

37 Chen LS, Goodson P: Factors affecting decisions to accept or decline cystic fibrosis carrier testing/screening: a theory-guided systematic review. Genet Med 2007; 9 ; 442-450.

38 Conway SP, Allenby K, Pond MN: Patient and parental attitudes toward genetic screening and its implications at an adult cystic fibrosis centre. Clin Genet 1994; 45 308-312; e-pub ahead of print 29 July 2015; doi:10.1038/ejhg.2015.160.

39 Janssens S, Chokoshvilli D, Binst C et al: Attitudes of cystic fibrosis patients and parents toward carrier screening and related reproductive issues. Eur J Hum Genet 2016; 24: 506-512.

40 Maxwell SJ, Kyne G, Molster C, Barker NM, Ormsby J, O'Leary P: Perceptions of population cystic fibrosis prenatal and preconception carrier screening among individuals with cystic fibrosis and their family members. Genet Test Mol Biomarkers 2011; 15: 159-164.

41 Clarke AJ: Genetic testing and genomic screening. In: Kumar D, Eng C (eds): Genomic Medicine: Principles and Practice, 2nd edn Oxford University Press: Oxford, UK, 2014, pp 224-225

42 Falik-Zaccai TC, Kfir N, Frenkel P et al: Population screening in a Druze community: the challenge and the reward. Genet Med 2008; 10: 903-909.

43 Basel-Vanagaite L, Taub E, Drasinover V et al: Genetic carrier screening for spinal muscular atrophy and spinal muscular atrophy with respiratory distress 1 in an isolated population in Israel. Genet Test 2008; 12: 53-56.

44 Zlotogora J, Carmi R, Lev B, Shalev SA: A targeted population carrier screening program for severe and frequent genetic diseases in Israel. Eur J Hum Genet 2008, 17: 591-597.

45 Mathijssen IB, Henneman L, Van Eeten-Nijman JM et al: Targeted carrier screening for four recessive disorders: high detection rate within a founder population. Eur J Med Genet 2015; 58: 123-128.

46 Ekstein J, Katzenstein $\mathrm{H}$ : The Dor Yeshorim story: community-based carrier screening for Tay-Sachs disease. Adv Genet 2001; 44: 297-310.

47 Frumkin A, Raz AE, Plesser-Duvdevani M, Lieberman S: 'The Most Important Test You'll Ever Take'?: attitudes toward confidential carrier matching and open individual testing among modern-religious Jews in Israel. Soc Sci Med 2011; 73: 1741-1747

48 Gason AA, Metcalfe SA, Delatycki MB et al: Tay Sachs disease carrier screening in schools: educational alternatives and cheekbrush sampling. Genet Med 2005; 7: 626-632.

49 Barlow-Stewart K, Burnett L, Proos A et al: A genetic screening programme for Tay-Sachs disease and cystic fibrosis for Australian Jewish high school students. J Med Genet 2003; 40: 45.

50 Leib JR, Gollust SE, Hull SC, Wilfond BS: Carrier screening panels for Ashkenazi Jews: is more better? Genet Med 2005; 7: 185-190.

51 Scott SA, Edelmann L, Liu L, Luo M, Desnick RJ, Kornreich R: Experience with carrier screening and prenatal diagnosis for 16 Ashkenazi Jewish genetic diseases. Hum Mutat 2010; 31: 1240-1250.

52 Hall J, Fiebig DG, King MT, Hossain I, Louviere JJ: What influences participation in genetic carrier testing?: results from a discrete choice experiment. $J$ Health Econom 2006; 25: 520-537.

53 Borry P, Clarke A, Dierickx K: Carrier screening: look before you leap: carrier screening for type 1 Gaucher disease: difficult questions. Eur J Hum Genet 2007; 16: 139-140.

54 Zuckerman S, Lahad A, Shmueli A: Carrier screening for gaucher disease: Lessons for low-penetrance, treatable diseases. JAMA 2007; 298: 1281-1290.

55 Holtkamp KC, Van Maarle MC, Schouten MJ, Dondorp WJ, Lakeman P, Henneman L: Do people from the Jewish community prefer ancestry-based or pan-ethnic expanded carrier screening? Eur J Hum Genet 2016; 24: 171-177.

56 Cao A, Rosatelli MC, Monni G, Galanello R: Screening for thalassemia: a model of success. Obstet Gynecol Clin North Am 2002; 29: 305-vii.

57 Van Elderen T, Mutlu D, Karstanje J, Passchier J, Tibben A, Duivenvoorden HJ: Turkish female immigrants' intentions to participate in preconception carrier screening for hemoglobinopathies in the Netherlands: an empirical study. Public Health Genomics 2010; 13: 415-423.
58 Van der Pal SM, Van Kesteren NM, Van Wouwe JP, Van Dommelen P, Detmar SB: The attitudes and intention to participate in hemoglobinopathy carrier screening in The Netherlands among individuals from Turkish, Moroccan, and Surinamese descent. J Environ Public Health 2013; 2013: 374831.

59 Ahmed S, Green JM, Hewison J: Attitudes towards prenatal diagnosis and termination of pregnancy for thalassaemia in pregnant Pakistani women in the North of England. Prenat Diagn 2006; 26: 248-257.

60 Gitsels-van der Wal JT, Mannien J, Ghaly MM, Verhoeven PS, Hutton EK, Reinders HS: The role of religion in decision-making on antenatal screening of congenital anomalies: a qualitative study amongst Muslim Turkish origin immigrants. Midwifery 2014; 30: 297-302.

61 Giordano PC, Dihal AA, Harteveld CL: Estimating the attitude of immigrants toward primary prevention of the hemoglobinopathies. Prenat Diagn 2005; 25: 885-893.

62 Lakeman P, Plass AM, Henneman L, Bezemer PD, Cornel MC, Ten Kate LP: Preconceptional ancestry-based carrier couple screening for cystic fibrosis and haemoglobinopathies: what determines the intention to participate or not and actua participation? Eur J Hum Genet 2009; 17: 999-1009.

63 Prior TW, Snyder PJ, Rink BD et al: Newborn and carrier screening for spinal muscular atrophy. Am J Med Genet A 2010; 152A: 1608-1616.

64 Martyn M, Anderson V, Archibald A et al: Offering fragile X syndrome carrier screening a prospective mixed-methods observational study comparing carrier screening of pregnant and non-pregnant women in the general population. BMJ Open 2013; 3: e003660.

65 Archibald AD, Jaques AM, Wake S, Collins VR, Cohen J, Metcalfe SA: 'It's something I need to consider': Decisions about carrier screening for fragile $X$ syndrome in a population of non-pregnant women. Am J Med Genet 2009; 149: 2731-2738.

66 Fanos JH, Spangner KA, Musci TJ: Attitudes toward prenatal screening and testing for Fragile X. Genet Med 2006; 8: 129-133.

67 Ames AG, Metcalfe SA, Dalton AA, Duncan RE, Emery J: Measuring informed choice in population-based reproductive genetic screening: a systematic review. Eur J Hum Genet 2015; 23: 8-21.

68 Clayton EW, Hannig VL, Pfotenhauer JP, Parker RA, Campbell PW III, Phillips JA III: Lack of interest by nonpregnant couples in population-based cystic fibrosis carrier screening. Am J Hum Genet 1996; 58: 617-627.

69 Henneman L, Bramsen I, Van Kempen L et al: Offering preconceptional cystic fibrosis carrier couple screening in the absence of established preconceptional care services. Community Genet 2003; 6: 5-13.

70 Henneman L, Poppelaars FA, Ten Kate LP: Evaluation of cystic fibrosis carrier screening programs according to genetic screening criteria. Genet Med 2002; 4: 241-249.

71 Bekker H, Modell M, Denniss G et al: Uptake of cystic fibrosis testing in primary care: supply push or demand pull? BMJ 1993; 306: 1584-1586.

72 Ahmad WI, Atkin K: Primary care and haemoglobin disorders: a study of families and professionals. Crit Public Health 2000; 10: 41-53.

73 Dormandy E, Gulliford M, Bryan S et al: Effectiveness of earlier antenatal screening for sickle cell disease and thalassaemia in primary care: cluster randomised trial. $\mathrm{Br} \mathrm{Med}$ J 2010; 341: c5132.

74 Van Agt HM, Korfage IJ, Essink-Bot ML: Interventions to enhance informed choices among invitees of screening programmes-a systematic review. Eur J Public Health 2014; 24: 789-801.

75 Canatan D, Aydinok Y, Kilinc $Y$ et al: National thalassemia prevention campaign: the talotir project. Turk J Haematol 2013; 30: 91-92.

76 Canatan D, Kose MR, Ustundag M, Haznedaroglu D, Ozbas S: Hemoglobinopathy control program in Turkey. Community Genet 2006; 9: 124-126.

77 Saffi M, Howard N: Exploring the effectiveness of mandatory premarital screening and genetic counselling programmes for beta-thalassaemia in the Middle East: a scoping review. Publ Health Genomics 2015; 18: 193-203.

78 Karimi M, Jamalian N, Yarmohammadi H, Askarnejad A, Afrasiabi A, Hashemi A: Premarital screening for beta-thalassaemia in Southern Iran: options for improving the programme. J Med Screen 2007; 14: 62-66.

79 Alswaidi FM, O'Brien SJ: Premarital screening programmes for haemoglobinopathies, HIV and hepatitis viruses: review and factors affecting their success. J Med Screen 2009; 16: 22-28.

80 Srinivasan BS, Evans EA, Flannick J et al: A universal carrier test for the long tail of Mendelian disease. Reprod Biomed Online 2010; 21: 537-551.

81 Bell CJ, Dinwiddie DL, Miller NA et al: Carrier testing for severe childhood recessive diseases by next-generation sequencing. Sci Trans/ Med 2011; 3: $65 \mathrm{ra} 4$.

82 Sikkema-Raddatz B, Johansson LF, de Boer EN et al: Targeted next-generation sequencing can replace Sanger sequencing in clinical diagnostics. Hum Mutat 2013; 34: $1035-1042$

83 Linderman MD, Brandt T, Edelmann $\mathrm{L}$ et al: Analytical validation of whole exome and whole genome sequencing for clinical applications. BMC Med Genomics 2014; 7: 20

84 Brownstein $\mathrm{CA}$, Beggs $\mathrm{AH}$, Homer $\mathrm{N}$ et al: An international effort towards developing standards for best practices in analysis, interpretation and reporting of clinical genome sequencing results in the CLARITY Challenge. Genome Biol 2014; 15: R53.

85 Weiss MM, Van der Zwaag B, Jongbloed JD et al: Best practice guidelines for the use of next-generation sequencing applications in genome diagnostics: a national collaborative study of Dutch genome diagnostic laboratories. Hum Mutat 2013; 34: 1313-1321. 
86 Peterlin B, Vidmar L, Borry P et al: Expanded carrier screening tests currently on the commercial market. Eur J Hum Genet 2014; 22(Suppl 1): 291.

87 Kingsmore S: Comprehensive carrier screening and molucular diagnostic testing for recessive childhood diseases. PLoS Curr 2012; e4f9877ab8ffa9.

88 Orphanet. Prevalence and incidence of rare diseases: Bibilographic data. Orphanet Report Series 2015, http:/www.orpha.net/orphacom/cahiers/docs/GB/Prevalence of rare_diseases_by_decreasing_prevalence_or_cases.pdf Last accessed 18 August 2015.

89 Lazarin GA, Haque IS, Nazareth S et al: An empirical estimate of carrier frequencies for 400+ causal Mendelian variants: results from an ethnically diverse clinical sample of 23,453 individuals. Genet Med 2013; 15: 178-186.

90 Francioli LC, Menelaou A, Puli SL et al: Whole-genome sequence variation, population structure and demographic history of the Dutch population. Nat Genet 2014; 46: 818-825.

91 Stenson PD, Mort M, Ball EV et al: The Human Gene Mutation Database: 2008 update. Genome Med 2009; 1: 13.

92 Borry P, Henneman L, Lakeman P, Ten Kate LP, Cornel MC, Howard HC: Preconceptional genetic carrier testing and the commercial offer directly-toconsumers. Hum Reprod 2011; 26: 972-977.

93 European Association for the Study of the Liver: EASL clinical practice guidelines for HFE hemochromatosis. J Hepatol 2010; 53: 3-22.

94 Bacon BR, Adams PC, Kowdley KV, Powell LW, Tavill AS: Diagnosis and management of hemochromatosis: 2011 practice guideline by the American Association for the Study of Liver Diseases. Hepatology 2011; 54: 328-343.

95 Dondorp W, De Wert G, Bombard Y et al: Non-invasive prenatal testing for aneuploidy and beyond: challenges of responsible innovation in prenatal screening. Eur J Hum Genet 2015; 23: 1438-1450.

96 Wertz DC, Knoppers BM: Serious genetic disorders: can or should they be defined? Am J Med Genet 2002; 108: 29-35.

97 Lazarin GA, Hawthorne F, Collins NS, Platt EA, Evans EA, Haque IS: Systematic classification of disease severity for evaluation of expanded carrier screening panels. PLoS One 2014; 9: e114391.

98 Anheim M, Elbaz A, Lesage S et al: Penetrance of Parkinson disease in glucocerebrosidase gene mutation carriers. Neurology 2012; 78: 417-420.

99 Sherman S, Pletcher BA, Driscoll DA: Fragile X syndrome: diagnostic and carrier testing. Genet Med 2005; 7: 584-587.

100 Schwartz B: The Paradox of Choice. Why More is Less. HarperCollins Publishers: New York, NY, USA, 2004.

101 Elias S, Annas GJ: Generic consent for genetic screening. N Engl J Med 1994; 330: $1611-1613$

102 Dondorp WJ, De Wert GM: The 'thousand-dollar genome': an ethical exploration. Eur J Hum Genet 2013; 21(Suppl 1): S6-S26.

103 Hewison J: Psychological aspects of individualized choice and reproductive autonomy in prenatal screening. Bioethics 2015; 29: 9-18.

104 Axworthy D, Brock DJ, Bobrow M, Marteau TM: Psychological impact of populationbased carrier testing for cystic fibrosis: 3-year follow-up. UK Cystic Fibrosis Follow-Up Study Group. Lancet 1996; 347: 1443-1446.

105 Lakeman P, Plass AM, Henneman L, Bezemer PD, Cornel MC, Ten Kate LP: Three-month follow-up of Western and non-Western participants in a study on preconceptional ancestry-based carrier couple screening for cystic fibrosis and hemoglobinopathies in the Netherlands. Genet Med 2008; 10: 820-830.

106 Ioannou L, Massie J, Collins V, McClaren B, Delatycki MB: Population-based genetic screening for cystic fibrosis: attitudes and outcomes. Public Health Genomics 2010; 13: 449-456.
107 Mennie ME, Compton ME, Gilfillan A et al: Prenatal screening for cystic fibrosis: psychological effects on carriers and their partners. J Med Genet 1993; 30: 543-548.

108 Wald NJ: Couple screening for cystic fibrosis. Lancet 1991; 338: 1318-1319.

109 Metcalfe S, Jacques A, Archibald A et al: A model for offering carrier screening for fragile $X$ syndrome to nonpregnant women: results from a pilot study. Genet Med 2008; 10: 525-535.

110 Cousens NE, Gaff CL, Delatycki MB, Metcalfe SA: Prenatal beta-thalassemia carrier screening in Australia: healthcare professionals' perspectives of clinical practice. Prenat Diagn 2014; 34: 246-250.

111 Cousens N, Gaff C, Metcalfe S, Delatycki M: He didn't say that thalassaemia might come up. Beta-thalassaemia carriers' experiences and attitudes. J Community Genet 2013; 4: 223-232.

112 Marteau TM, van DM, Ellis I: Effects of genetic screening on perceptions of health: a pilot study. J Med Genet 1992; 29: 24-26.

113 Henneman L, Bramsen I, Van der Ploeg HM, Ten Kate LP: Preconception cystic fibrosis carrier couple screening: impact, understanding, and satisfaction. Genetic Testing 2002; 6: 195-202.

114 Payne Y, Williams M, Cheadle J et al: Carrier screening for cystic fibrosis in primary care: evaluation of a project in South Wales. The South Wales Cystic Fibrosis Carrier Screening Research Team. Clin Genet 1997; 51: 153-163.

115 Gordon C, Walpole I, Zubrick SR, Bower C: Population screening for cystic fibrosis: knowledge and emotional consequences 18 months later. Am J Med Genet A 2003; 120A: 199-208.

116 Raz AE, Vizner Y: Carrier matching and collective socialization in community genetics: Dor Yeshorim and the reinforcement of stigma. Soc Sci Med 2008; 67: 1361-1369.

117 Markel H: The stigma of disease: implications of genetic screening. Am J Med 1992; 93: 209215.

118 Kenen RH, Schmidt RM: Stigmatization of carrier status: social implications of heterozygote genetic screening programs. Am J Public Health 1978; 68: 1116-1120.

119 Lakeman P, Henneman L, Bezemer PD, Cornel MC, Ten Kate LP: Developing and optimizing a decisional instrument using self-reported ancestry for carrier screening in a multi-ethnic society. Genet Med 2006; 8: 502-509.

120 Delatycki MB, Wolthuizen M, Collins V et al: IronXS: high-school screening for hereditary haemochromatosis is acceptable and feasible. Eur J Hum Genet 2012; 20: 505-509.

121 Fears R, Ter Meulen VEASAC-FEAM Working Group: The perspective from EASAC and FEAM on direct-to-consumer genetic testing for health-related purposes. Eur J Hum Genet 2013; 21: 703-707.

(c) (i) (2) (2) This work is licensed under a Creative Commons Attribution-NonCommercial-ShareAlike 4.0 International License. The images or other third party material in this article are included in the article's Creative Commons license, unless indicated otherwise in the credit line; if the material is not included under the Creative Commons license, users will need to obtain permission from the license holder to reproduce the material. To view a copy of this license, visit http:// creativecommons.org/licenses/by-nc-sa/4.0/ 